\title{
Short-Channel Structured Reactor as a Catalytic Afterburner
}

\author{
M. Iwaniszyn · J. Ochońska • A. Gancarczyk • \\ P. Jodłowski • A. Knapik · J. Lojewska $\cdot$ \\ E. Janowska-Renkas $\cdot$ A. Kołodziej
}

Published online: 8 March 2013

(c) The Author(s) 2013. This article is published with open access at Springerlink.com

\begin{abstract}
Short-channel structures of triangular and sinusoidal channel cross-sectional shape were examined experimentally to find their heat (or mass) transfer and flow friction (flow resistance) characteristics. A particular emphasis was placed on influence of the channels length (referred to its hydraulic diameter) on transport and hydrodynamic characteristics. The transport and friction properties were correlated in terms of dimensionless channel length with satisfactory accuracy. The dimensionless channel length was proved to be a key factor that determines the transport and friction coefficients. Comparison with ceramic monolith has shown possibility of using the structures in automotive catalytic converters.
\end{abstract}

Keywords Structured reactor - Heat transfer .

Mass transfer - Flow resistance .

Dimensionless channel length

\author{
Abbreviation \\ List of Symbols \\ a $\quad$ Specific surface area, $\mathrm{m}^{-1}$ \\ A, B Constants \\ $\mathrm{C}_{\mathrm{D}} \quad$ Drag coefficient
}

M. Iwaniszyn $(\bowtie) \cdot$ A. Gancarczyk · A. Kołodziej

Institute of Chemical Engineering, Polish Academy of Sciences,

Bałtycka 5, 44-100 Gliwice, Poland

e-mail: miwaniszyn@iich.gliwice.pl

J. Ochońska · P. Jodłowski · A. Knapik · J. Łojewska

Faculty of Chemistry, Jagiellonian University, Ingardena 3,

30-060 Kraków, Poland

E. Janowska-Renkas · A. Kołodziej

Faculty of Civil Engineering, Opole University of Technology,

Katowicka 48, 45-061 Opole, Poland
$\mathrm{D}_{\mathrm{A}} \quad$ Kinematic diffusivity, $\mathrm{m}^{2} \mathrm{~s}^{-1}$

$\mathrm{D}_{\mathrm{h}} \quad 4 \varepsilon / \mathrm{a}$, hydraulic diameter, $\mathrm{m}$

$\mathrm{D}_{\mathrm{p}} \quad$ Grains diameter, $\mathrm{m}$

f Fanning friction factor

Gz Graetz number

$\mathrm{k}_{\mathrm{C}} \quad$ Mass transfer coefficient, $\mathrm{m} \mathrm{s}^{-1}$

L Channel length, $\mathrm{m}$

$\mathrm{L}^{+} \quad \mathrm{L} /\left(\mathrm{D}_{\mathrm{h}} \cdot \mathrm{Re}\right)$, hydraulic dimensionless channel length

$\mathrm{L}^{*} \quad \mathrm{~L} /\left(\mathrm{D}_{\mathrm{h}} \cdot \mathrm{Re} \cdot \mathrm{Pr}\right)$, heat dimensionless channel length

$\mathrm{L}^{* \mathrm{M}} \quad \mathrm{L} /\left(\mathrm{D}_{\mathrm{h}} \cdot \mathrm{Re} \cdot \mathrm{Sc}\right)$, mass dimensionless channel length

$\mathrm{Nu} \quad \alpha \cdot \mathrm{D}_{\mathrm{h}} / \lambda$, Nusselt number

$\operatorname{Pr} \quad \mathbf{C}_{\mathrm{p}} \cdot \eta / \lambda$, Prandtl number

$\operatorname{Re} \quad w_{0} \cdot \rho \cdot D_{h} /(\varepsilon \cdot \eta)$, Reynolds number

Sc $\quad \eta /\left(\rho \cdot D_{h}\right)$, Schmidt number

Sh $\quad k_{C} \cdot D_{h} / D_{A}$, Sherwood number

$\mathrm{w}_{0} \quad$ Superficial gas velocity, $\mathrm{m} \mathrm{s}^{-1}$

$\alpha \quad$ Heat transfer coefficient, $\mathrm{W} \mathrm{m}{ }^{-2} \mathrm{~K}^{-1}$

$\Delta \mathrm{P} \quad$ Pressure drop (flow resistance), $\mathrm{Pa}$

$\varepsilon \quad$ Void volume

$\eta \quad$ Dynamic viscosity, Pa s

$\lambda$ Thermal conductivity, $\mathrm{W} \mathrm{m}^{-1} \mathrm{~K}^{-1}$

$\rho \quad$ Density, $\mathrm{kg} \mathrm{m}^{-3}$

\section{List of Subscripts}

fd Fully developed flow

$\mathrm{H}$ Boundary condition of constant heat flux

$\mathrm{T}$ Boundary condition of constant surface temperature

tr Triangular structure

sn Sinusoidal structure

\section{Introduction}

During last decades, structured reactors-mainly classic monoliths_-have achieved remarkable success, mainly due 
to their application as automotive converters. However, in spite of amazingly low flow resistance, their further utilization is limited by insufficient heat and mass transfer. Therefore, new reactor fillings are still being invented to simultaneously improve transfer properties and keep flow resistance at a satisfactory low level. Due to sustained progress in designing more and more active catalysts and resulting from that enhanced kinetics of catalytic reactions, mass transfer to the catalyst becomes a limiting factor leading to excessive reactor length and unnecessary consumption of precious catalyst.

Classic monoliths can be described as a bunch of capillary channels, in which laminar gas flow occurs. Within the regime of fully developed laminar flow, fluid velocity, or Reynolds number, weakly influences transport properties. Nevertheless, near to the channel inlet, in the entrance (or mixing) section, a so-called developing laminar flow leads to highly enhanced heat and mass transport; which simultaneously gives rise to undesirable increase in flow resistance. A promising way to intensify a process can thus be to "cut" monolith to force developing laminar flow in a major part of the channel. Such an idea was proposed recently by Kołodziej et al. [1-3].

The aim of this work was to experimentally study shortchannel structures [1-3]. Heat transfer and flow resistances were studied for short-channel structures of triangular and sinusoidal cross-sectional shape within large range of Reynolds numbers. The channel lengths of both the triangular and sinusoidal structures amounted 5, 10, 15 and $20 \mathrm{~mm}$. For comparison, research presented in [3] was performed using $3 \mathrm{~mm}$ long structures. This study follows the approach and nomenclature in our previous papers [1-3] following Shah and London [4].

\section{Experimental}

The experimentally tested structures, shown in Fig. 1, are composed of straight and wavy (or zigzag) strips of the Kanthal steel containing chromium, aluminium and cobalt. The wavy/zigzag strips are twice as long as the straight ones. Therefore, they were also made twice as thick compared to the strait ones to ensure similar electrical resistance, and thus heat evolved during experiments. The parameters of the examined structures as well as of the ceramic monolith and packed bed chosen for comparison are gathered in Table 1.

The experimental method described by Kołodziej et al. [3] and by Kołodziej and Łojewska [5] was applied. A test reactor of rectangular cross-section, $45 \times 30 \mathrm{~mm}$, was used for flow resistance and heat transfer experiment. Applied range of Reynolds numbers was from 13 till 2,880. The metallic structures studied were heated by strong electric current (up to $150 \mathrm{~A}$ ) flowing directly through them. The thermal losses were carefully balanced and taken into account. Three thermocouples measured inlet and outlet temperature of the flowing air, respectively. Six thermocouples measured surface temperatures of a metallic structure (three near to the entrance and three near to the end). The thermocouples were attached to the channel walls using special composite glue that secured good heat conduction and no electric conduction. The flow resistance was measured using the Recknagel micromanometer.

\section{Results and Discussion}

\subsection{Flow Resistance}

The flow resistance is expressed in terms of Fanning friction factor $f$ :

$f=\frac{\Delta P}{L} \frac{\varepsilon^{2} D_{h}}{2 w_{0}^{2} \rho}$

and correlated as a function of dimensionless hydraulic channel length $\mathrm{L}^{+}=\mathrm{L} /\left(\mathrm{D}_{\mathrm{h}} \cdot \mathrm{Re}\right)$, according to the approach of Shah and London [4]. According to Shah [7], for the fully developed laminar flow the product value $(f \cdot R e)_{f d}$ amounts to $(f \cdot R e)_{f d}=13,333$ for triangular channel and $(f \cdot R e)_{f d}=$ 11,256 for sinusoidal channel. Theoretical solution of Fleming and Sparow [6] for developing laminar flow in triangular channels can be correlated as $[1,3]$ :

$(f \cdot \operatorname{Re})=(f \cdot \operatorname{Re})_{f d}+0.8031 \cdot\left(L^{+}\right)^{-0.731}$

A similar form of correlation equation was accepted in this study following the approach in former research [1-3]:

$(f \cdot \operatorname{Re})=(f \cdot \operatorname{Re})_{f d}+A \cdot\left(L^{+}\right)^{B}$

Figure 2 presents the flow resistance results obtained for all the examined structures. Individual correlations were derived for both triangular and sinusoidal structures of different channel lengths. The constants $\mathrm{A}$ and $\mathrm{B}$ of individual correlations derived for particular structures as well as average correlation errors are gathered in Table 1 .

It is noticeable in Fig. 2 that the longer the channel length, the lower the Fanning friction factors are and the experimental points lie closer to the theoretical solution of Fleming-Sparow [6]. It was impossible to describe all the triangular (or sinusoidal) structures with single, general correlation in spite of good experimental accuracy. The differences were ascribed to the drag forces that acted on the front surface (edge) of the structures. This influence is almost the same for all the structures regardless of their length, however, its share in the total flow resistance is inversely proportional to the channel 
Fig. 1 Short-channel structures, a sinusoidal, b triangular
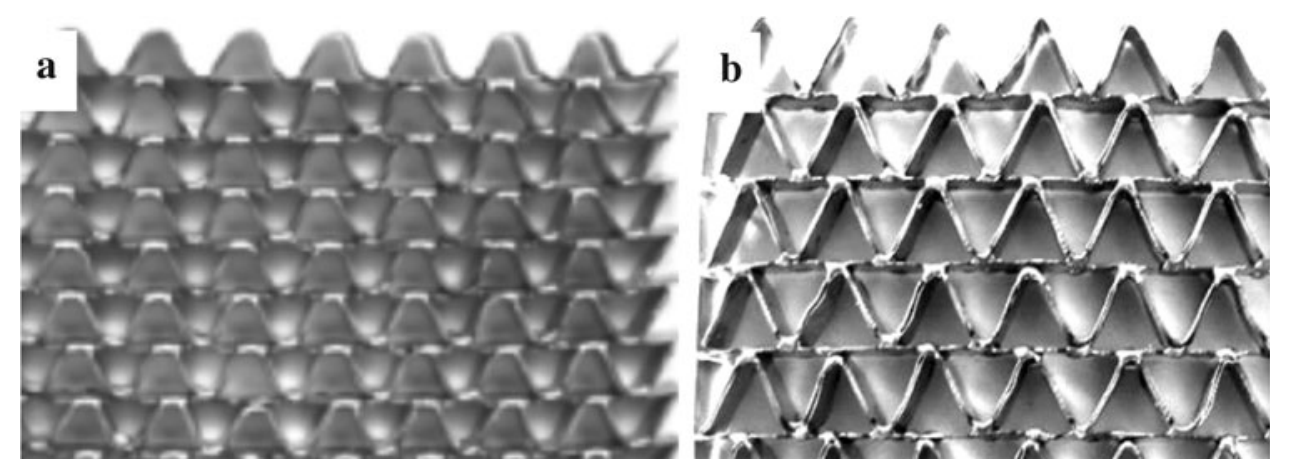

Table 1 Geometrical parameters of the short-channel structures and reactor fillings taken for comparison

\begin{tabular}{|c|c|c|c|c|c|c|c|}
\hline \multirow[t]{2}{*}{ Structure description } & \multirow{2}{*}{$\begin{array}{l}\text { Length L } \\
(\mathrm{mm})\end{array}$} & \multirow{2}{*}{$\begin{array}{l}\text { Specific surface } \\
a\left(\mathrm{~m}^{-1}\right)\end{array}$} & \multirow{2}{*}{$\begin{array}{l}\text { Void } \\
\text { volume }(\varepsilon)\end{array}$} & \multirow{2}{*}{$\begin{array}{l}\text { Hydraulic diameter } \\
\mathrm{D}_{\mathrm{h}}(\mathrm{mm})\end{array}$} & \multicolumn{3}{|c|}{ Friction factor $f$, Eq. (3) } \\
\hline & & & & & A & B & $\begin{array}{l}\text { Average } \\
\text { error }(\%)\end{array}$ \\
\hline \multirow{4}{*}{$\begin{array}{l}\text { Triangular short-channel structure } \\
\text { base } 5.5 \mathrm{~mm} \text {; height } 4.5 \mathrm{~mm}\end{array}$} & 5 & 1314 & 0.945 & 2.88 & 16.58 & -0.486 & 10.9 \\
\hline & 10 & & & & 11.59 & -0.514 & 7.0 \\
\hline & 15 & & & & 11.56 & -0.467 & 10.8 \\
\hline & 20 & & & & 9.33 & -0.495 & 9.7 \\
\hline \multirow{4}{*}{$\begin{array}{l}\text { Sinusoidal short-channel structure } \\
\text { base } 4 \mathrm{~mm} \text {; height } 2.15 \mathrm{~mm}\end{array}$} & 5 & 2383 & 0.904 & 1.52 & 8.54 & -0.489 & 9.8 \\
\hline & 10 & & & & 6.96 & -0.451 & 9.2 \\
\hline & 15 & & & & 8.05 & -0.453 & 8.9 \\
\hline & 20 & & & & 7.82 & -0.397 & 10.4 \\
\hline Monolith $400 \mathrm{cpsi}$ & 200 & 2709 & 0.85 & 1.26 & & & \\
\hline Packed bed of $2 \mathrm{~mm}$ spheres & - & 1570 & 0.48 & 2.0 & & & \\
\hline
\end{tabular}

Experimentally derived constants (A, B) of individual correlations for Fanning friction factor, according to Eq. (2), are given in last three columns with the correlation average error

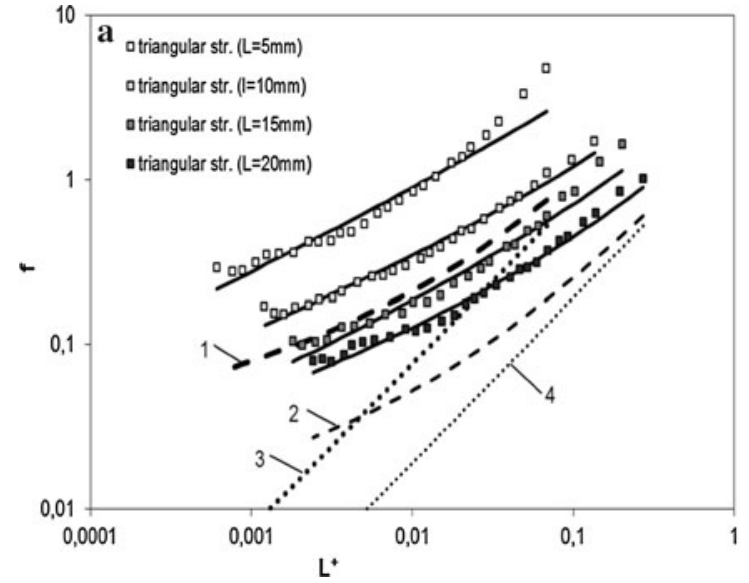

Fig. 2 Flow resistance results (selected experimental points) in terms of Fanning friction factors versus hydraulic dimensionless channel length $\mathrm{L}^{+}$for structures: a triangular, b sinusoidal. 1 Fleming-Sparow

length. The total pressure drop is assumed to be the sum of drag (inertial) resistance and viscous resistance (skin friction):

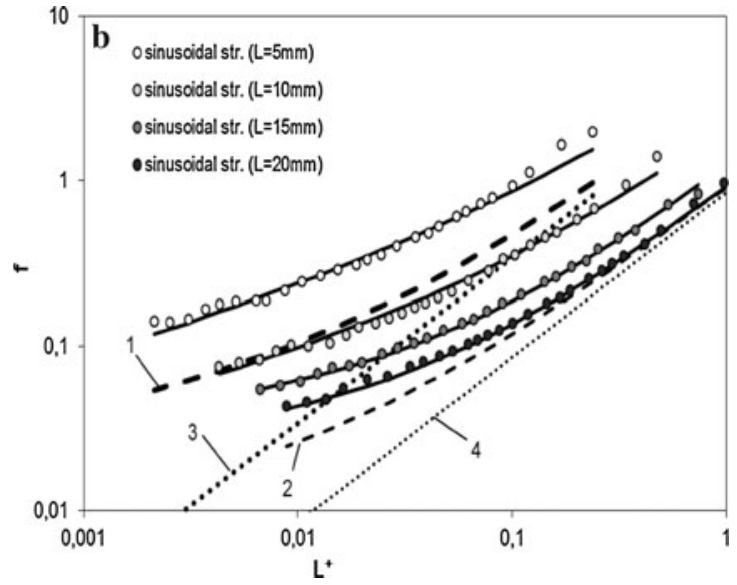

[6] for $\mathrm{L}=5 \mathrm{~mm}$; 2 Fleming-Sparow [6] for $\mathrm{L}=20 \mathrm{~mm}$; 3 Shah [7] for $\mathrm{L}=5 \mathrm{~mm}$; 4 Shah [7] for $\mathrm{L}=20 \mathrm{~mm}$

$\Delta P=\Delta P_{\text {viscous }}+\Delta P_{\text {drag }}=4 f \frac{\rho w_{0}^{2}}{2 \varepsilon^{2}} \frac{L}{D_{h}}+C_{D} \frac{\rho w_{0}^{2}}{2} \frac{(1-\varepsilon)}{\varepsilon^{2}}$ 
Both the Fanning friction factor $f$ and the drag coefficient $C_{D}$ are assumed to be functions of Reynolds number:

$f=\frac{A_{1}}{\operatorname{Re}}+A_{2} \quad \operatorname{Re}=\frac{w_{0} \rho D_{h}}{\varepsilon \eta}$

$C_{D}=\frac{B_{1}}{\operatorname{Re}_{D}}+B_{2} \quad \operatorname{Re}_{D}=\frac{w_{0} \rho s}{\varepsilon \eta} \quad s=\frac{2(1-\varepsilon)}{a}$

Drag force is proportional to cross-section of solid that is proportional to $(1-\varepsilon)$. Reynolds number, $\operatorname{Re}_{\mathrm{D}}$, that characterizes drag forces have another characteristic dimension-average thickness of a sheets from which a structure is made (s, cf. Eq. (6)). This approach is similar to that applied by Wieghardt [8] or Chhabra and Richardson [9] during modeling of flow through wire meshes. For both triangular and sinusoidal structures coefficients $\mathrm{A}_{1,2}$ and $\mathrm{B}_{1,2}$ were estimated assuming that the length of the structure (L) does not influence the drag coefficient $C_{D}$ (i.e. coefficients $\mathrm{B}_{1,2}$ ). The following results were found:

- triangular structure: $\mathrm{A}_{1}=6.46 ; \mathrm{A}_{2}=0.0253 ; \mathrm{B}_{1}=$ $346 ; \mathrm{B}_{2}=27.1$; average error $6.2 \%$;

- $\quad$ sinusoidal structure: $\mathrm{A}_{1}=5.86 ; \mathrm{A}_{2}=0.0174 ; \mathrm{B}_{1}=$ $178 ; \mathrm{B}_{2}=14.1$; average error $6.1 \%$.

Resulting Fanning friction factors (reflecting viscous friction) and drag coefficients (reflecting drag flow resistance) are presented in Fig. 3. Fanning friction factor found by Fleming and Sparow [6] for laminar flow developing in triangular channel is shown for comparison. Friction factors for triangular and sinusoidal structures are similar to each other and up to $50 \%$ lower than the theoretical prediction in [7]. Drag coefficients reported for flat plane perpendicular to the flow direction is about $C_{D}=2$,

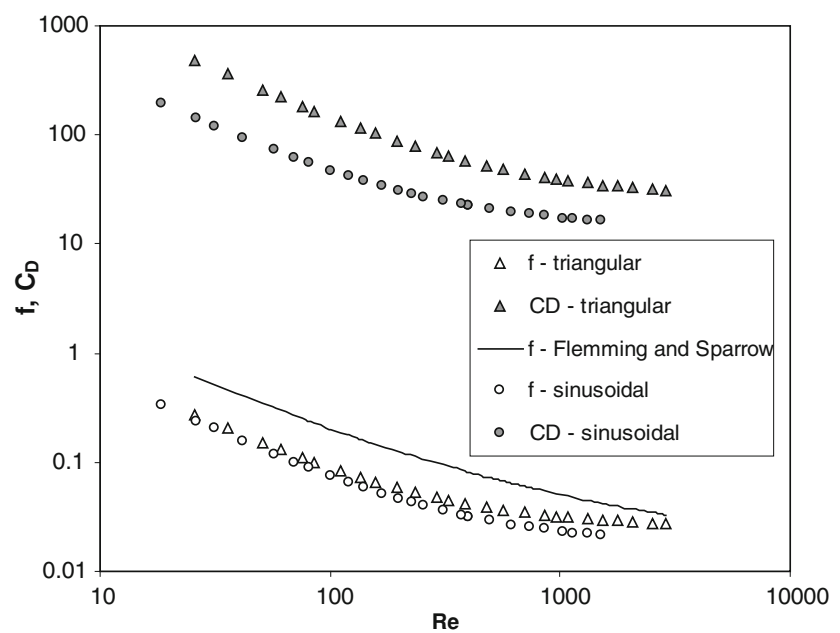

Fig. 3 Estimated values of Fanning friction factor $\mathrm{f}$ and drag coefficient $C_{D}$ for triangular and sinusoidal structures (selected points), compared with the results of Fleming and Sparow [6] however, for significantly higher Reynolds numbers; for the range studied the data are hardly available.

\subsection{Heat and Mass Transfer}

Heat transfer results expressed as Nusselt number are assumed to be a function of the heat dimensionless channel length $\mathrm{L}^{*}$ (reciprocal of the Graetz number) according to Shah and London [4]:

$L^{*}=\frac{L}{D_{h} \operatorname{Re} \operatorname{Pr}}=\frac{\pi}{4} \frac{1}{G z}$

Based on the tabularized theoretical data of Wibulswas [10], the correlations have been derived for laminar flow developing in the triangular channel and for the boundary conditions $\langle\mathrm{T}\rangle$ (constant wall temperature, $\mathrm{Nu}_{\mathrm{T}}$ ) and $\langle\mathrm{H}\rangle$ (constant heat flux, $\mathrm{Nu}_{\mathrm{H}}$ ):

$$
\begin{aligned}
& N u_{T}=2.47+0.299 \cdot\left(L^{*}\right)^{-0.598} \\
& N u_{H}=3.111+0.448 \cdot\left(L^{*}\right)^{-0.608}
\end{aligned}
$$

For the fully developed laminar flow, $\mathrm{Nu}_{\mathrm{T}}=2.47$ and $\mathrm{Nu}_{\mathrm{H}}=3.111$ [4].

Kołodziej et al. [3] have proposed semi-empirical correlations that are the products of the Wibulswas' solutions [10] and the correction terms derived from the experimental results; similar approach is used in this study. The heat transfer results for triangular and sinusoidal structures are correlated, respectively:

$$
\begin{aligned}
& N u_{t r}=N u_{H}\left[0.547\left(\operatorname{Pr} \cdot L^{*}\right)^{-0.146}\right] \\
& N u_{s n}=N u_{T}\left[0.535\left(\operatorname{Pr} \cdot L^{*}\right)^{-0.177}\right]
\end{aligned}
$$

The average errors of the above correlations are: $12.1 \%$ (triangular) and $17.8 \%$ (sinusoidal structure).

The mass transfer solutions were derived using the heat and mass transfer analogy. Such methodology was applied and experimentally confirmed in [5]; broader discussion is presented in [11]. The constants in mass transfer equations are the same as in the heat transfer ones in light of the analogy assumed. Equation (10) reflect the data of Wibulswas [10] and Eq. (11) experimental results of this research:

$$
\begin{aligned}
& S h_{T}=2.47+0.299 \cdot\left(L^{* M}\right)^{-0.598} \\
& S h_{H}=3.111+0.448 \cdot\left(L^{* M}\right)^{-0.608} \\
& S h_{t r}=S h_{H}\left[0.547\left(S c \cdot L^{* M}\right)^{-0.146}\right] \\
& S h_{s n}=S h_{T}\left[0.535\left(S c \cdot L^{* M}\right)^{-0.177}\right]
\end{aligned}
$$

Above, $\mathrm{L}^{* \mathrm{M}}=\mathrm{L} /\left(\mathrm{D}_{\mathrm{h}} \cdot \mathrm{Re} \cdot \mathrm{Sc}\right)$ is the mass dimensionless channel length. The mass transfer results for both structures are presented in Fig. 4. 

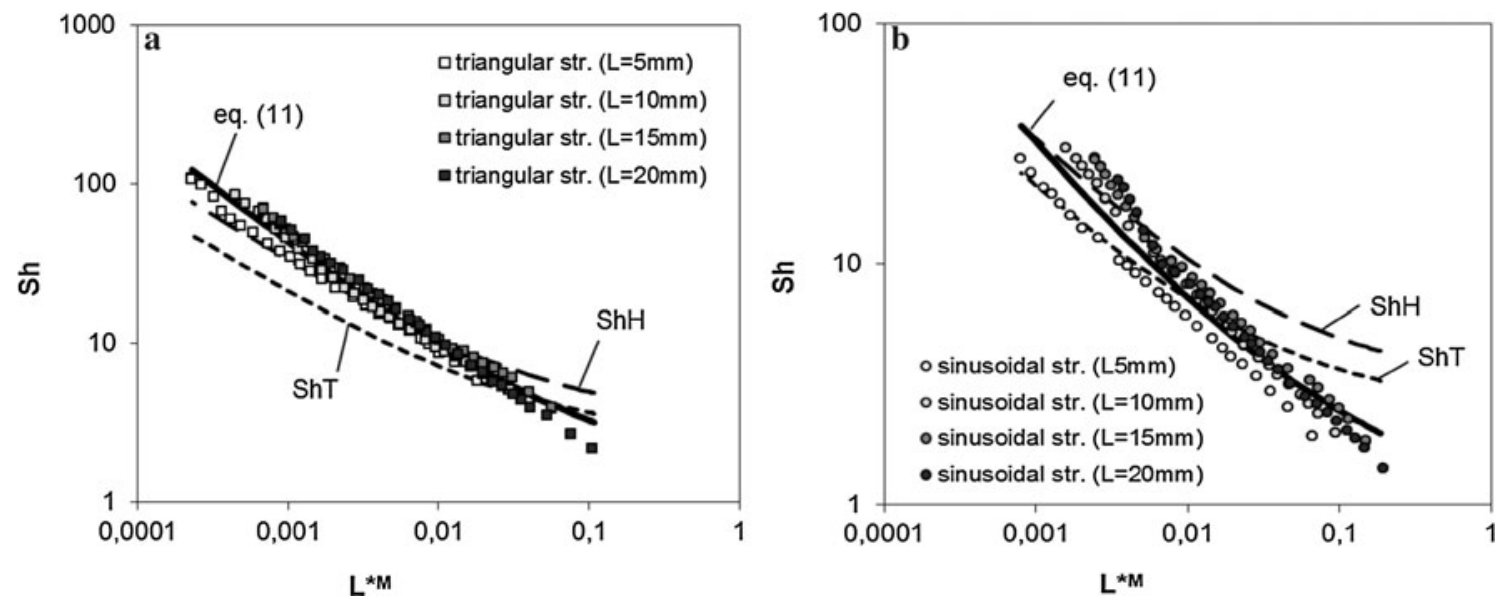

Fig. 4 The mass transfer results (selected experimental points) for structures: a triangular, b sinusoidal (Sherwood numbers vs. mass dimensionless channel length $\mathrm{L}^{* \mathrm{M}}$ ). $S h_{H}, S h_{T}$ theoretical solutions of Wibulswas [10] for $\langle\mathrm{H}\rangle$ and $\langle\mathrm{T}\rangle$ boundary condition, respectively Eq. (10)

Sherwood numbers obtained for triangular structure lie close to the Wibulswas' [10] theoretical solution for $\langle\mathrm{H}\rangle$ boundary condition; however, for very small Re (i.e. large $\left.L^{*}\right)$ values experimental points tend to the $\langle T\rangle$ solution. When considering the sinusoidal structures, the results are close to the solution for $\langle\mathrm{H}\rangle$ boundary condition for large $\operatorname{Re}$ (or small $\mathrm{L}^{*}$ ). For small Re (large $\mathrm{L}^{*}$ ) the points lie close to the $\langle\mathrm{T}\rangle$ solution or even below. The tendency is therefore similar for both kinds of structures and seems realistic. For large Reynolds numbers, high heat transfer coefficients extort large heat transferred to gas phase and boundary condition $\langle\mathrm{H}\rangle$ (constant heat flux) is fulfilled. On the other hand, for small Re (i.e. low heat transfer intensity) heat flux inside metallic surface body might be comparable with the heat transferred to the gas phase; this may lead to surface temperature equalizing (Fig. 4).

\subsection{Comparison with Monolith and Packed Bed}

Mass transfer and flow friction for the structures have been compared with ceramic monolith (400 cpsi-channels per square inch) and with packed bed of $2 \mathrm{~mm}$ beads. Sherwood numbers and Fanning friction factors of the monolith was calculated using Hawthorn [12] equations. Friction factor for packed bed was derived from Ergun [13] equation, Sherwood number using Wakao and Kaguei correlation [14]. The comparison is shown in Figs. 5 and 6 for the mass transfer and flow resistance, respectively.

Comparison of diverse reactor fillers shows that mass transfer of the structures is more intensive than that of monolith, while their flow resistance is only slightly higher. Moreover, structures display similar, or even slightly better, mass transfer intensity than packed bed. On the other hand, flow resistance of structures is much lower when comparing with a classic dumped bed. Significantly higher

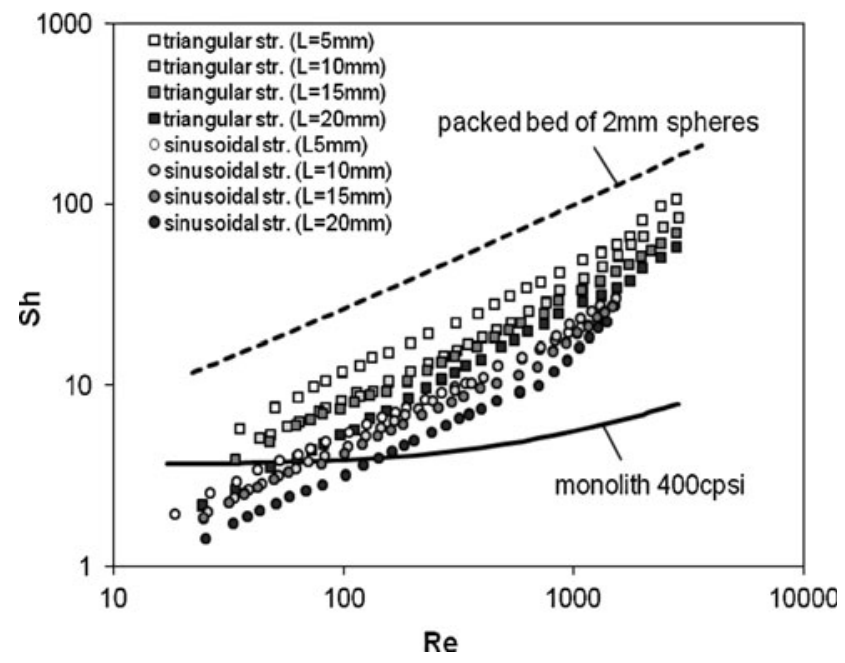

Fig. 5 Mass transfer for different reactor fillings

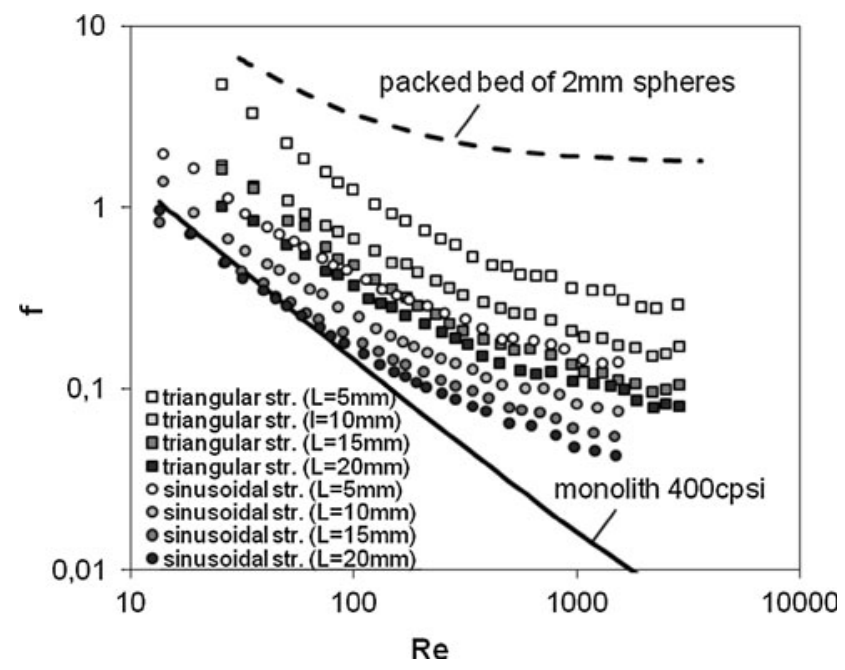

Fig. 6 Flow resistance for different reactor fillings 
mass transfer rates enable to avoid mass transfer limitations that are frequent problems connected with fast catalytic reactions. Based on our former study [2], mass transfer intensity enhanced till 10 times may lead to reduction of the reactor length by 10-40 times compared with classic monolith, however, under condition of very fast chemical reaction.

\section{Conclusions}

- Short-channel structures offer significantly higher mass (or heat) transfer compared with monolith, paid by only slight increase of flow resistance. Their mass transfer is comparable with packed bed but flow resistance is much lower.

- By changing the length of the structures it is possible to precisely adjust their flow resistance and transfer properties to individual demands of the process.

- Short-channel structures open possibility of successful catalytic reactor optimization.

- High share of the drag flow resistance suggests need of appropriate shape design of the structure edges.

Acknowledgments This work was supported by BRIDGE Programme grant (No 2010-1/4) within the Foundation for Polish Science co-financed by the EU Structured Funds, partly within the Foundation for Polish Science MPD Programme co-financed by the EU European
Regional Development Fund and by the research grant from the Polish National Science Centre No. 2011/03/B/ST8/05455.

Open Access This article is distributed under the terms of the Creative Commons Attribution License which permits any use, distribution, and reproduction in any medium, provided the original author(s) and the source are credited.

\section{References}

1. Kołodziej A, Łojewska J (2007) Chem Eng Process 46:637

2. Kołodziej A, Łojewska J (2007) Top Catal 42-43:475

3. Kołodziej A, Łojewska J, Ochońska J, Łojewski T (2011) Chem Eng Process 50:869

4. Shah RK, London AL (1978) Laminar flow forced convection in ducts. Academic, New York

5. Kołodziej A, Łojewska J (2009) Catal Today 147S:S120

6. Fleming DP, Sparow EM (1969) J Heat Transf 91:345

7. Shah RK (1975) Int J Heat Mass Transf 18:849

8. Wibulswas P.: Laminar-flow heat-transfer in non-circular ducts. Ph.D. Thesis, London University (1966)

9. Iwaniszyn M, Jaroszyński M, Ochońska J, Łojewska J, Kołodziej A (2011) Scientific Publications of IICh PAN 15:37. http://www. iich.gliwice.pl/files/303/Zeszyt $\% 2015 \% 20$ (2011).pdf. Accessed 5 Feb 2013

10. Hawthorn RD (1974) AIChE Symp Ser 70(137):428

11. Wieghardt KEG (1953) Aeronaut Quart 4:186

12. Chhabra RP, Richardson JF (1985) Chem Eng Sci 40:313

13. Ergun S (1952) Chem Eng Prog 48:89

14. Wakao N, Kaguei S (1982) Heat and mass transfer in packed beds. Gordon and Breach Science Publisher, New York 